\title{
ApoE deficiency exacerbates the development and sustainment of a semi-chronic K/BxN serum transfer-induced arthritis model
}

\author{
Amy M. Archer ${ }^{1 \neq}$, Rana Saber ${ }^{1 \neq}$, Shawn Rose ${ }^{1,2 \ddagger}$, Alexander Shaffer ${ }^{1}$, Alexander V. Misharin ${ }^{1,3}$, FuNien Tsai ${ }^{1}$, \\ G. Kenneth Haines $1 \mathrm{II}^{4}$, Salina Dominguez ${ }^{1}$, Mesut Eren ${ }^{5}$, Douglas E. Vaughan ${ }^{5}$, Carla M. Cuda ${ }^{{ }^{*} \dagger}$ \\ and Harris Perlman ${ }^{1 *+}$
}

\begin{abstract}
Background: The risk for developing cardiovascular disease is greater in patients with rheumatoid arthritis (RA) than in the general population. While patients with RA also have dyslipidemia, the impact of dyslipidemia on the severity of inflammatory arthritis and associated cardiovascular disease is unclear. Currently, there are conflicting results regarding arthritis incidence in apolipoprotein E (ApoE) deficient mice, which spontaneously exhibit both hyperlipidemia and atherosclerosis. Here, we utilize a distinct approach to investigate the contribution of a hyperlipidemic environment on the development of arthritis and atherosclerosis in mice lacking ApoE.

Methods: K/BxN serum transfer-induced arthritis (STIA) was assessed in C57BL/6 (control) and ApoE ${ }^{-/}$mice using clinical indices and immunohistochemical staining. Ankle synoviums were processed for flow cytometry. Aortic atherosclerosis was quantitated using Sudan IV staining. Serum cholesterol and cytokine levels were determined via enzymatic and luminex bead-based assays, respectively.

Results: $\mathrm{ApoE}^{-/-}$mice developed a sustained and enhanced semi-chronic inflammatory arthritis as compared to control mice. ApoE ${ }^{-/-}$mice had increased numbers of foamy macrophages, enhanced joint inflammation and amplified collagen deposition versus controls. The presence of arthritis did not exacerbate serum cholesterol levels or significantly augment the level of atherosclerosis in $\mathrm{ApoE}^{-1-}$ mice. However, arthritic $\mathrm{ApoE}^{-1-}$ mice exhibited a marked elevation of IL-6 as compared to non-arthritic ApoE ${ }^{-1-}$ mice and arthritic C57BL/6 mice.

Conclusions: Loss of ApoE potentiates a semi-chronic inflammatory arthritis. This heightened inflammatory response was associated with an increase in circulating $\mathrm{IL}-6$ and in the number of foamy macrophages within the joint. Moreover, the foamy macrophages within the arthritic joint are reminiscent of those within unstable atherosclerotic lesions and suggest a pathologic role for foamy macrophages in propagating arthritis.
\end{abstract}

Keywords: Arthritis, Cholesterol, Inflammation, Animal models of human disease

\footnotetext{
*Correspondence: c-cuda@northwestern.edu;

h-perlman@northwestern.edu

${ }^{\dagger}$ Carla M. Cuda and Harris Perlman share senior authorship

${ }^{\ddagger}$ Amy M. Archer, Rana Saber and Shawn Rose contributed equally to this

work

${ }^{1}$ Division of Rheumatology, Department of Medicine, Northwestern

University Feinberg School of Medicine, 240 East Huron Street, McGaw

M338, Chicago, IL 60611, USA

Full list of author information is available at the end of the article
} 


\section{Background}

Rheumatoid arthritis (RA) is a chronic, systemic, autoimmune disease associated with significant disability and increased mortality [1]. Life expectancy is reduced in patients with RA, largely due to the development of premature cardiovascular disease [2, 3]. Patients with RA have roughly a $50-60 \%$ increase in the risk of death from cardiovascular causes compared to the general population [4]. This elevated cardiovascular risk is independent of traditional risk factors and may be due to increased systemic inflammation in RA [3].

Atherosclerotic disease is a major cause of cardiovascular morbidity and mortality. One of the primary determinants of the propensity of atherosclerotic plaques to rupture and subsequently cause vascular occlusion is the stability of the foamy macrophages within the plaques [5]. Foamy macrophages are formed through the uptake of oxidized LDL through scavenger receptors, such as CD36. When foamy macrophages become saturated with oxidized LDL cell death can occur, which results in the release of proinflammatory cellular contents and formation of a necrotic core within the atherosclerotic plaque [5]. The understanding of this process has been facilitated by the use of ApoE knockout mice [6,7] since functional mutations in ApoE lead to elevations in serum cholesterol levels and premature atherosclerosis in both mice and humans $[8,9]$.

The role that dyslipidemia plays in the development of atherosclerosis in RA is highly controversial. Numerous studies have shown that patients with RA have reduced total cholesterol (TC) levels compared to controls, which may be attributed to the increased inflammatory burden present in RA [10]. Surprisingly, decreases in TC are associated with adverse cardiovascular outcomes in patients with RA [11]. However, the atheroprotective effects of high-density lipoprotein (HDL) may be dampened in RA, as patients with more active disease exhibit reduced HDL-mediated cholesterol efflux as compared to patients with quiescent disease [12].

Conversely, the impact of the presence of hyperlipidemia on the development of inflammatory arthritis is also unclear. The collagen-induced arthritis (CIA) model [13] has previously been utilized to examine the development of arthritis and atherosclerosis in $\mathrm{ApoE}^{-/-}$mice, but has led to conflicting results. One group found that $\mathrm{ApoE}^{-1-}$ mice were resistant to CIA [14], while another group showed that $\mathrm{ApoE}^{-1-}$ mice developed more severe disease [15]. Thus the uncertainty of the role that dyslipidemia plays in the progression of arthritis in RA and whether the changes in lipid profile associated with inflammatory arthritis can alter the progression of atherosclerosis in a hyperlipidemic setting further underscores the critical need to utilize murine models of altered cholesterol metabolism to better understand these processes.

Here, we examined the development of arthritis in $\mathrm{ApoE}^{-1-}$ mice compared to controls using a semi-chronic $\mathrm{K} / \mathrm{BxN}$ serum transfer-induced arthritis (STIA) model [16]. The STIA model mimics the effector phase of RAlike disease and does not require lymphocytes. $\mathrm{ApoE}^{-1-}$ mice developed enhanced semi-chronic inflammatory arthritis as compared to control mice. Elevated foamy macrophage numbers were observed in the synovial lining and extra-articular tissue from $\mathrm{ApoE}^{-1-}$ mice, but not in controls. Moreover, arthritic $\mathrm{ApoE}^{-1-}$ mice secreted increased levels of circulating pro-inflammatory IL-6. However, the degree of arthritis failed to significantly impact dyslipidemia or atherosclerotic disease burden in $\mathrm{ApoE}^{-/-}$mice on a high fat diet. These data suggest that a dyslipidemic environment can alter the progression of inflammatory arthritis during the effector phase of disease. Further, these data support a potential pathogenic role for foamy macrophages not only in atherosclerotic lesions, but also within the arthritic joint.

\section{Methods \\ Animals}

For generation of arthritogenic serum, KRN mice were kindly provided by Drs. Diane Mathis and Christophe Benoist, and non-obese diabetic mice were purchased from Taconic, Germantown, NY. Male and female wildtype control mice (C57BL/6, Jackson Laboratory, Bar Harbor, ME) and $\mathrm{ApoE}^{-/-}$mice, which spontaneously exhibit both hyperlipidemia and atherosclerosis (Jackson Laboratory-B6.129P2-Apoe ${ }^{\text {tm1Unc } / J}$ stock number 002052), were purchased from commercial vendors. Genotyping was confirmed by Transnetyx (Memphis, $\mathrm{TN})$. Mice were maintained on chow until 8 weeks of age and then switched to Harlan Teklad Western diet TD.94059 (Harlan Technologies, Houston, TX) containing $15.8 \%$ fat and $1.25 \%$ cholesterol. Animals were bred and maintained in a barrier facility within the Center for Comparative Medicine and were approved by the Northwestern University IACUC.

\section{Scoring and induction of arthritis}

For acute $\mathrm{K} / \mathrm{BxN}$ serum transfer-induced arthritis (STIA), animals received a single injection of $50 \mu \mathrm{l}$ of $\mathrm{K} /$ BxN serum at 12 weeks of age as previously described [17-19]. STIA involves the passive transfer of arthritogenic anti-glucose-6-phosphate isomerase antibodies. The arthritis that ensues in these mice has almost $100 \%$ penetrance and the mice develop maximum arthritis within 1 week after each injection of $\mathrm{K} / \mathrm{BxN}$ serum. Arthritis severity was determined via the change in thickness of the hind paw ankle joints and a clinical 
score (total $=12$ ) for all four paws, where $0=$ normal, $1=$ swollen wrist, $2=$ swelling extending to dorsal paw, $3=$ swelling extending to the digits. Acute arthritis severity was assessed every other day via clinical score for 2 weeks. Semi-chronic K/BxN STIA was elicited in $\mathrm{ApoE}^{-1-}$ and control (C57BL/6) mice using $50 \mu \mathrm{l}$ of $\mathrm{K} /$ BxN serum every 2-3 weeks as previously described $[17,20]$. Animals were scored weekly for arthritis severity.

\section{Tissue preparation and flow cytometry}

Peripheral blood was harvested by cardiac puncture, followed by ventricular perfusion with $20 \mathrm{ml}$ of PBS. Aortas were excised, fixed in $4 \%$ paraformaldehyde and stained with Sudan IV (Sigma-Aldrich, St. Louis, MO). Ankles were either fixed in $10 \%$ formalin, decalcified and then paraffin embedded prior to immunohistochemistry or processed for flow cytometry as previously described [17]. Data were acquired on BD LSR II flow cytometer. Additional file 1 lists antibodies, clones, fluorochromes and manufacturers used for all flow cytometric studies. The following dyes were utilized: fixable Viability Dye eFluor 506 from eBioscience and BoDIPY 493/503 from Molecular Probes. Compensation and analysis of the flow cytometry data were performed using FlowJo software (TreeStar).

\section{Immunohistochemistry}

Paraffin-embedded ankle sections were stained with haematoxylin and eosin, picrosirius red, rat anti-mouse F4/80 (clone BM8, Caltag) antibody or CD45 (Caltag) antibody and were scored for severity of disease by a pathologist $(\mathrm{GKH})$ blinded to the conditions as previously described [20-23]. Imaging was performed using an Olympus DP40 microscope (Tokyo, Japan) equipped with a DP71 camera or a Zeiss upright AXIO (TissueGnostics $\mathrm{GmbH}$ ) with a polarizing filter at the Northwestern Cell Imaging Facility (supported by NCI CCSG P30 CA060553 awarded to Robert H Lurie Comprehensive Cancer Center). Acquisition and analysis of picrosirius red staining utilized Tissue FAXS and TissueQuest. The picrosirius red quantification represents the sum of trans mean intensity for each tissue section.

\section{Serum analysis}

Serum TC, low-density lipoprotein/very low-density lipoprotein (LDL/vLDL) and HDL cholesterol levels were measured using enzymatic assays in accordance with the manufacturer's instructions (AbCam, Cambridge, MA). Serum cytokine and chemokine levels were assessed using Luminex (Austin, TX) Panomics 16-plex assays (Affymetrix, Santa Clara, CA) according to the manufacturer's instructions.

\section{Evaluation of atherosclerosis}

Atherosclerosis was quantified by computer-assisted morphometric analysis (Cell sense and ImagePro 6.3 software) of whole aortic (aortic root to iliac bifurcation) specimens. Results were expressed as the percentage of Sudan IV-stained lesion area (calculated by Sudan IV stained area/total aortic area $\times 100)$.

\section{Statistical analysis}

GraphPad Prism 5.0 Software (GraphPad Software, San Diego CA, USA) was utilized for all statistical analyses. Two-way ANOVA with Bonferroni posttests were used for arthritis analyses. Mann-Whitney U tests were used for histologic scoring, Sudan IV staining, levels of cytokines and chemokines, flow cytometry analysis, TC, LDL/vLDL and HDL levels among groups of mice. Statistical significance was established at $\mathrm{p}<0.05$.

\section{Results \\ ApoE $^{-/-}$mice exhibit greater severity of semi-chronic arthritis than control mice}

There are conflicting data concerning the effect of ApoE deficiency on the development of inflammatory arthritis in the CIA model $[14,15]$. Here we employed a different model of RA-like disease, the STIA model, which mimics the effector phase of RA and does not require the adaptive immune response. When the traditional STIA model was utilized (i.e., single injection of serum), we observed no difference in arthritis severity between $\mathrm{ApoE}^{-/-}$mice and C57BL/6 mice over a 2-week period (Additional file 2). However, this acute model represents a shorter time frame than the CIA model and does not provide adequate time for atherosclerotic plaques to develop. Therefore we employed a modified semi-chronic version of the STIA model, where animals were injected with K/ BxN serum every 2 weeks starting at 8 weeks of age and the development of arthritis was scored weekly over a 2-4 month period [24].

Throughout the development of semi-chronic arthritis $\mathrm{ApoE}^{-/-}$mice demonstrated significantly $(\mathrm{p}<0.001)$ more severe inflammatory arthritis as compared to C57BL/6 mice (Fig. 1). The clinical scores were also associated with the presence of histologically assessed inflammation. Ankle joint histologic severity scores of inflammation were elevated 2.3-fold in arthritic $\mathrm{ApoE}^{-1-}$ mice compared to C57BL/6 mice (Fig. 2a, b). Additionally, extra-articular inflammation was increased 7.7 -fold in arthritic $\mathrm{ApoE}^{-/-}$mice compared to $\mathrm{C} 57 \mathrm{BL} / 6$ mice (Fig. 2a, b). The histologic appearance of the extraarticular inflammation resembled that of a vulnerable atherosclerotic plaque, which is unstable and thus has an increased risk of progressing from a non-obstructive lesion to a vascular occlusion [25]. Although there were 


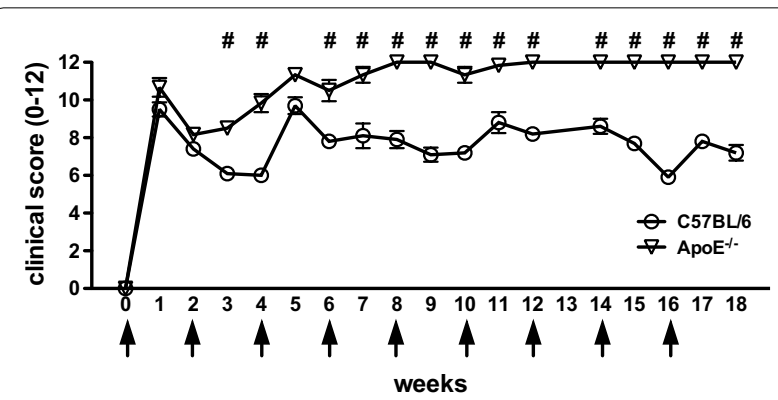

Fig. 1 Semi-chronic arthritis is more severe in $\mathrm{ApoE}^{-/-}$mice compared to C57BL/6 mice. C57BL/6 (control) and $\mathrm{ApoE}^{-/-}$mice $(n=4-5$ mice/group) were fed chow until 8 weeks of age, at which time they were fed a Western diet for an additional 2-4 months. Animals received serial injections of $\mathrm{K} / \mathrm{BxN}$ serum every $2-3$ weeks, beginning at 8 weeks of age. Arthritis severity was assessed weekly via clinical score. Data are represented as mean \pm SEM. Asterisk denotes statistically significant differences: ${ }^{\#} \mathrm{p}<0.001$ for $\mathrm{ApoE}^{-/-}$as compared to control mice. Arrows indicate time of injections

not significant differences in the total number of $\mathrm{F} 4 / 80^{+}$ macrophages or in the number of $\mathrm{F} 4 / 80^{+}$macrophages within the synovial lining or pannus (Fig. 3a, b), when we focused on the subset of $\mathrm{F} 4 / 80^{+}$macrophages that were histologically consistent with foamy macrophages there was a marked increase in this particular population of macrophages in $\mathrm{ApoE}^{-/-}$mice as compared to $\mathrm{C} 57 \mathrm{BL} / 6$ mice (Fig. 3a, b). Moreover, foamy macrophages represented the overwhelming majority of $\mathrm{F} 4 / 80^{+}$cells within the pannus and synovial lining in $\mathrm{ApoE}^{-/-}$mice. In most of the synoviums, the foamy macrophages resided beneath the synovial lining but in some cases they were mixed within the synovial cell lining. The surface lining cells in $\mathrm{ApoE}^{-1-}$ synoviums also showed variable foam cell morphology. In addition to the higher level of inflammation surrounding the foamy macrophages, there was a 1.5-fold increase in the amount of picrosirius red staining, indicative of collagen deposition, in arthritic ApoE $^{-1-}$ mice as compared to C57BL/6 mice (Fig. 4a, b). This illustrates another parallel between the pathology surrounding foamy macrophages within the synovium and those within atherosclerotic lesions. Taken together, these results indicate that $\mathrm{ApoE}^{-1-}$ mice demonstrate enhanced arthritis compared to $\mathrm{C} 57 \mathrm{BL} / 6$ mice.

\section{ApoE deficiency alters synovial macrophages characteristics}

The development of acute arthritis has been shown to be associated with a progressive change in the cellular composition of immune cells within the joint, particularly macrophages [17]. We previously established our ability to identify at least two different populations of synovial macrophages $\left(\mathrm{MHCII}^{+}\right.$and $\left.\mathrm{MHCII}^{-}\right)$using flow cytometry [17]. Therefore, we analyzed the impact of semi-chronic STIA on synovial macrophage composition in $\mathrm{ApoE}^{-1-}$ mice. Total numbers of synovial macrophages did not differ between $\mathrm{ApoE}^{-/-}$and $\mathrm{C} 57 \mathrm{BL} / 6$ mice with semi-chronic STIA (Fig. 5a). However, the higher ratio of $\mathrm{MHCII}^{+}$to $\mathrm{MHCII}^{-}$macrophages was more pronounced both at baseline and in the presence of semi-chronic arthritis in $\mathrm{ApoE}^{-1-}$ compared to C57BL/6 mice (Fig. 5b). In addition, both $\mathrm{MHCII}^{+}$and $\mathrm{MHCII}^{-}$synovial macrophages in $\mathrm{ApoE}^{-/-}$mice displayed increased expression of CD36, a scavenger receptor that is involved in the uptake of oxidized lipoproteins (Fig. $5 \mathrm{c}-\mathrm{e}$ ). Both $\mathrm{MHCII}^{-}$and $\mathrm{MHCII}^{+}$foamy synovial macrophages exhibited a higher uptake of lipophilic dye in $\mathrm{ApoE}^{-/-}$mice (Fig. 5f-h) and had higher side scatter (Fig. 5i-k), consistent with an increased accumulation of lipids within the cytoplasm.

\section{Arthritis does not impact atherosclerosis susceptibility in $\mathrm{ApoE}^{-/-}$mice}

We have previously shown that induction of inflammatory arthritis led to the development of atherosclerosis in mice [20]. To determine if inflammatory arthritis exacerbates atherosclerosis in $\mathrm{ApoE}^{-/-}$mice, a known model of hyperlipidemia-induced atherosclerosis, atherosclerotic lesion area via Sudan IV staining was investigated following STIA. Both C57BL/6 (Fig. 6a, b) and $\mathrm{ApoE}^{-1-}$ (Fig. 6c, d) mice exhibited a trend towards increased atherosclerosis in the presence of STIA with a 2-fold and 1.4-fold increase, respectively (Fig. 6e). When $\mathrm{ApoE}^{-1-}$ mice were compared to $\mathrm{C} 57 \mathrm{BL} / 6$ there was a 5.2-fold increase in area of atherosclerosis in the absence of arthritis and a 3.6-fold increase in the area of atherosclerosis in the presence of arthritis (Fig. 6e). These data demonstrate that inflammatory arthritis has a minimal impact on the high level of atherosclerosis that is already present in $\mathrm{ApoE}^{-/-}$mice on a high fat diet.

\section{Serum cholesterol levels are elevated in $\mathrm{ApoE}^{-/-}$mice}

To determine whether induction of arthritis alters serum cholesterol profiles in $\mathrm{ApoE}^{-/-}$and $\mathrm{C} 57 \mathrm{BL} / 6$ mice, levels of TC, LDL/vLDL and HDL were measured in serum from semi-chronic STIA animals (Fig. 7). Serum levels of both TC (Fig. 7a) and LDL/vLDL (Fig. 7b) were significantly greater in arthritic $\mathrm{ApoE}^{-/-}$mice (2.5-fold for TC and 3.6-fold for LDL/vLDL) compared to arthritic C57BL/6 mice. HDL levels were $38 \%$ lower in arthritic $\mathrm{ApoE}^{-1-}$ mice compared to arthritic C57BL/6 animals (Fig. 7c). However, there were no significant intra-genotype differences in lipid profile upon induction of STIA. These data suggest that although baseline lipid profiles are substantially different between $\mathrm{ApoE}^{-/-}$and $\mathrm{C} 57 \mathrm{BL} / 6$ 


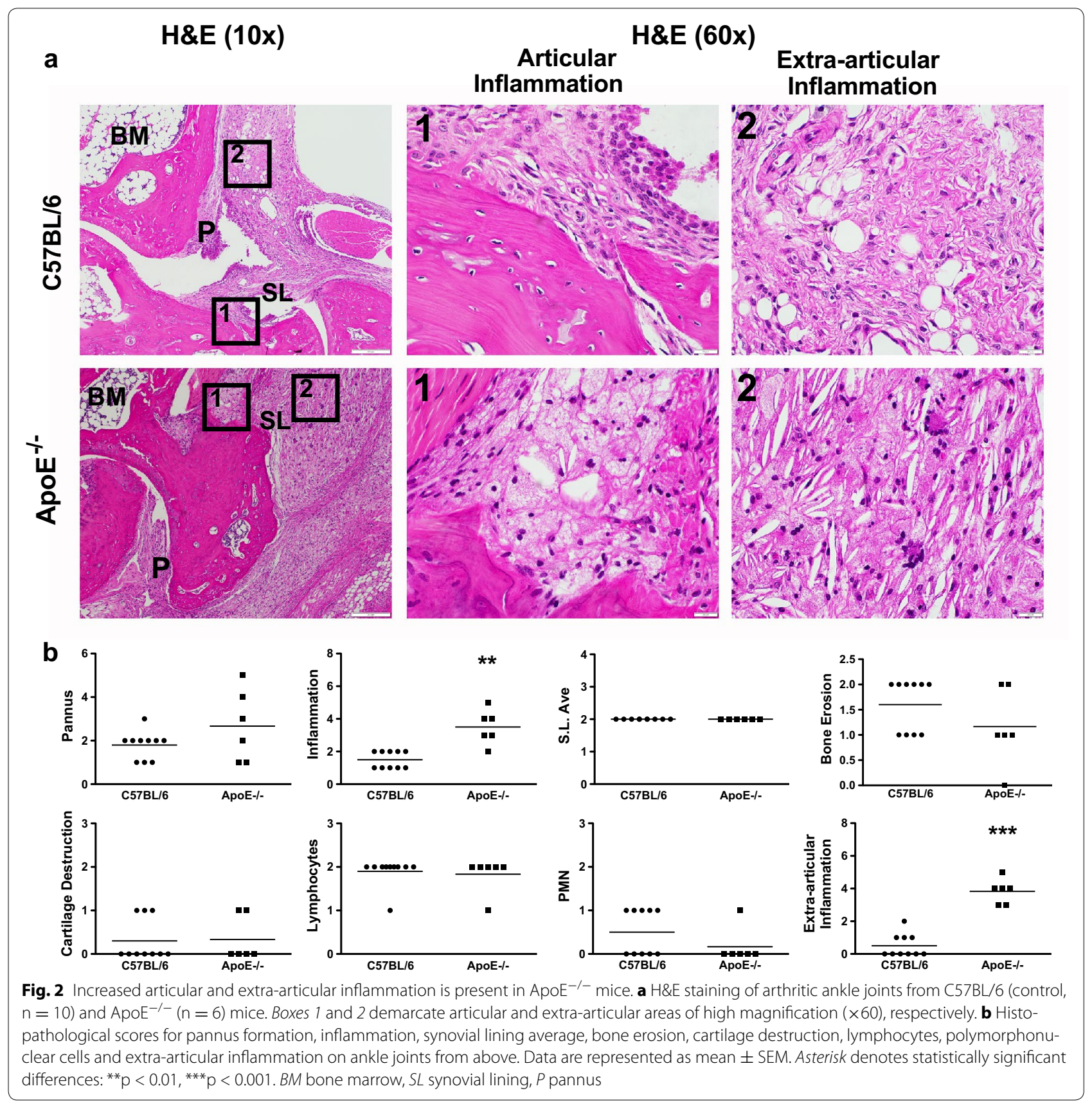

control mice, the induction of arthritis does not significantly change the lipid levels in $\mathrm{ApoE}^{-/-}$mice.

\section{IL-6 levels are enhanced in arthritic ApoE ${ }^{-/-}$mice}

Cytokines and chemokines are central to the development of inflammatory arthritis in both humans and mice [1]. To determine which inflammatory mediators may be responsible for the increased disease severity observed in $\mathrm{ApoE}^{-/-}$mice during semi-chronic arthritis, circulating levels of cytokines and chemokines were measured in
$\mathrm{ApoE}^{-1-}$ and $\mathrm{C} 57 \mathrm{BL} / 6$ mice with and without arthritogenic $\mathrm{K} / \mathrm{BxN}$ serum. The analysis included IL- $1 \alpha$, IL- $1 \beta$, TNF- $\alpha$, KC, MCP-1, IL-10, TGF- $\beta$, IL-4, IL-13, IL-2, IL-6, IFN- $\gamma$, IL-12p70, IL-17A, RANKL and IL-12/23p40 (Fig. 8; Additional file 3). Although the presence of arthritis in $\mathrm{ApoE}^{-/-}$mice was associated with increased levels of G-CSF, KC/Gro-a and decreased levels of IL-21, IL-23 and MIP-2 (Additional file 3), the greatest change was observed in IL-6 (Fig. 8). The induction of arthritis was correlated with a 27 -fold increase of serum IL-6 in 
a
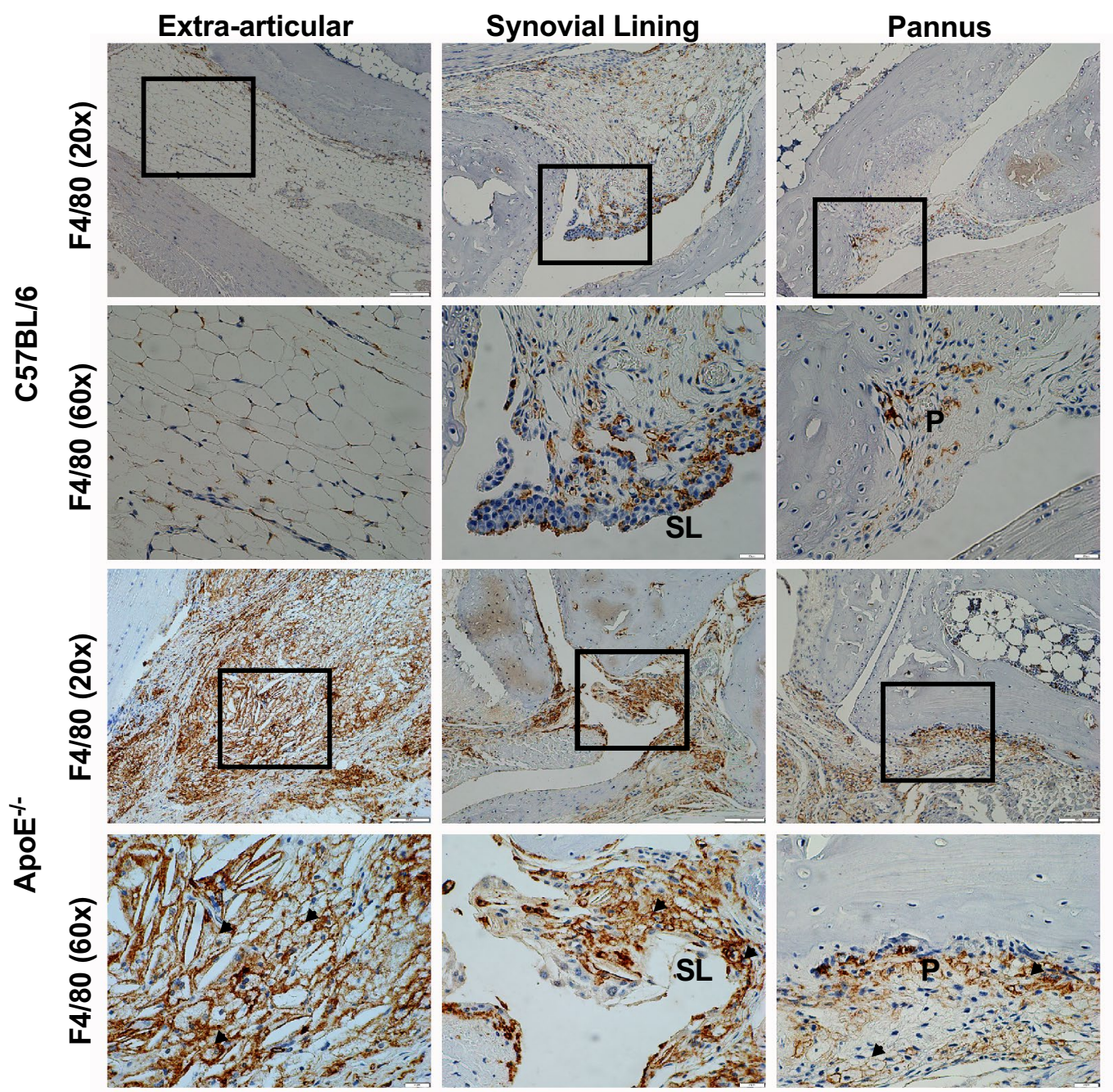

b
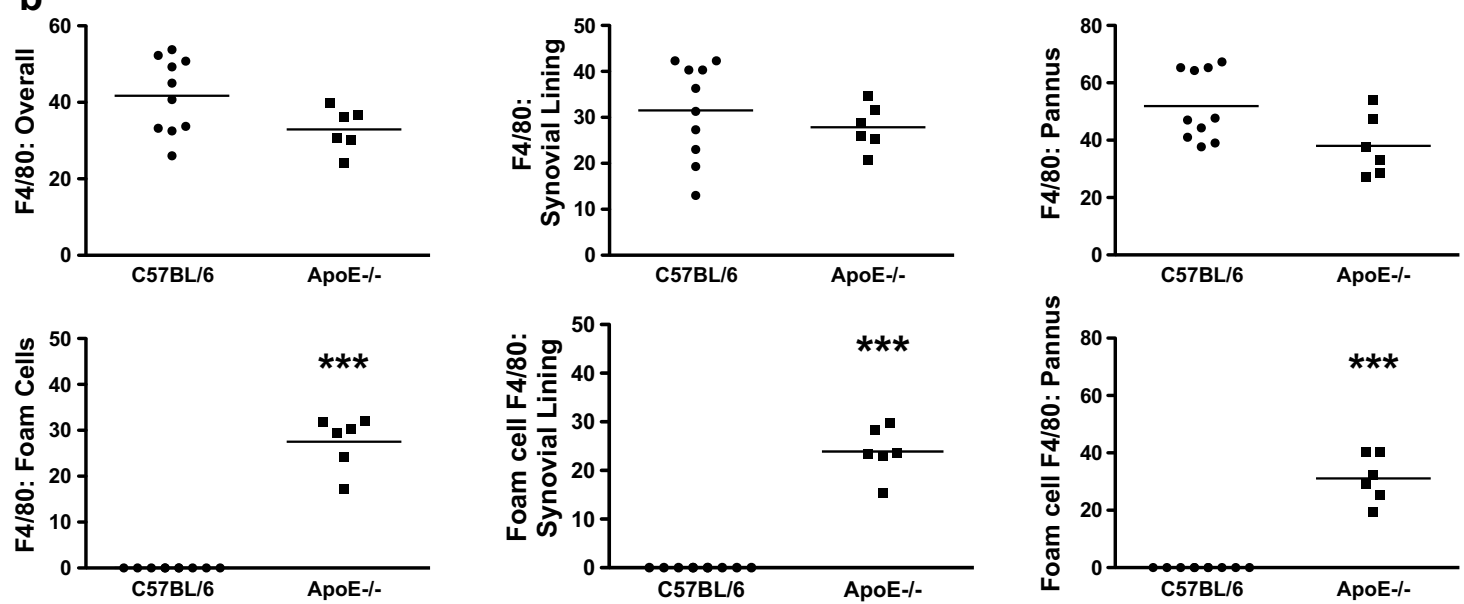

Fig. 3 Arthritic $\mathrm{ApoE}^{-/-}$mice have increased $\mathrm{F} 4 / 80^{+}$foam cells. a Photomicrographs of $\mathrm{F} 4 / 80$-stained extra-articular tissue, synovial lining and pannus of arthritic C57BL/6 (control, $n=10)$ and $\operatorname{ApoE}^{-/-}(n=6)$ mice. Squares delineate area of higher magnification shown below the respective image. $\mathbf{b}$ Immunohistopathological scores for $\mathrm{F} 4 / 80^{+}$total cells, $\mathrm{F} 4 / 80^{+}$cells within synovial lining and $\mathrm{F} 4 / 80^{+}$cells within the pannus from control and $\mathrm{ApoE}^{-/-}$mice. F4/80+ foam cells within each of these categories are subsequently quantified from the mice described above. Data are represented as mean $\pm \mathrm{SEM}$. Asterisk denotes statistically significant differences: ${ }^{* *} \mathrm{p}<0.001$. SL synovial lining, $P$ pannus, arrowheads foamy macrophages 


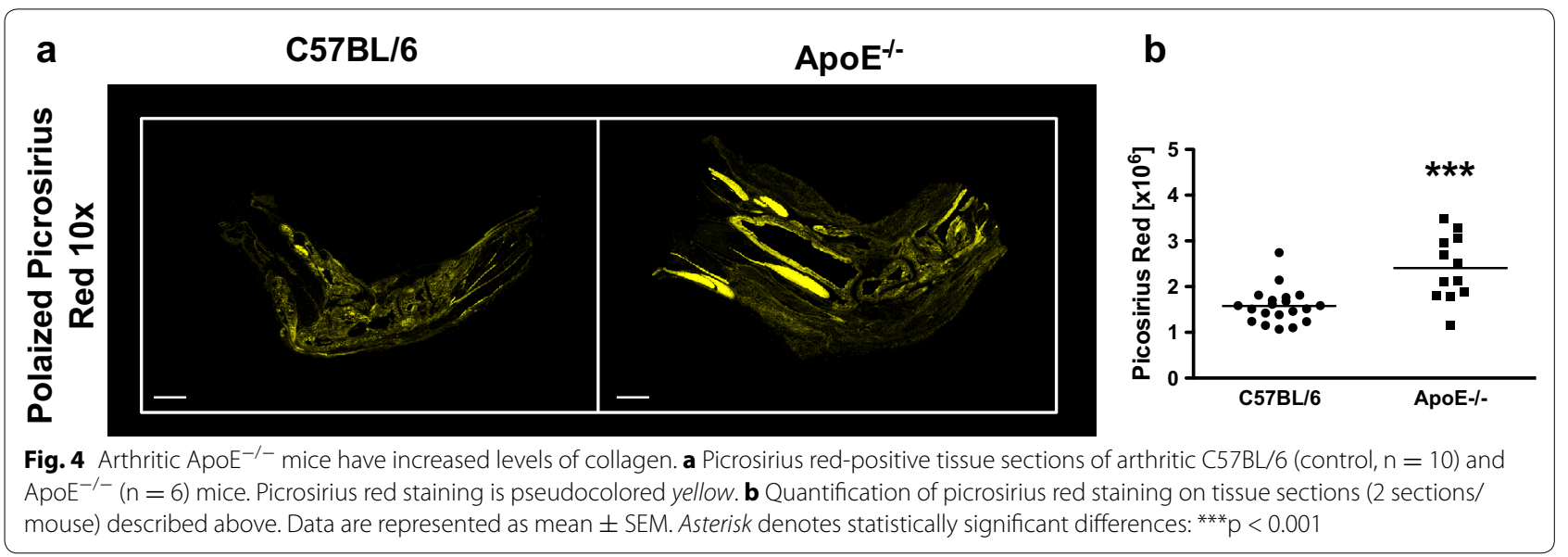

arthritic ApoE $\mathrm{A}^{-/-}$mice compared to arthritic C57BL/6 mice (Fig. 8). As IL-6 is a known mediator of both atherosclerosis and RA, our data suggest a potential role for this pro-inflammatory cytokine in our model.

\section{Discussion}

The role that dyslipidemia plays in the development of arthritis in murine models of RA remains controversial. Here, we utilized the semi-chronic STIA model of inflammatory arthritis since this model resembles the effector phase of RA and does not require the adaptive immune response. We show that $\mathrm{ApoE}^{-/-}$mice, which spontaneously develop hyperlipidemia and atherosclerosis, also exhibit a heightened level of inflammatory arthritis when compared to control mice. This heightened inflammation is associated with an increased number of foamy macrophages in the synovium and elevated serum IL-6 levels. Nonetheless, the presence of inflammatory arthritis is not associated with changes in atherosclerosis or hyperlipidemia in $\mathrm{ApoE}^{-/-}$mice. These data suggest that ApoE may play a novel suppressive role in inflammatory arthritis.

Currently, there are a plethora of therapeutics to treat dyslipidemia in RA patients. However, treatment of RA patients with atorvastatin, a cholesterol lowering medication, has been shown to decrease swollen joint count [26]. Further, previous studies using hypercholesterolemic mice to evaluate the relationship between dyslipidemia and inflammatory arthritis have yielded conflicting results. Prior studies utilized the CIA model to assess atherosclerosis and arthritis in $\mathrm{ApoE}^{-1-}$ mice $[14,15]$. Asquith et al. found that $\mathrm{ApoE}^{-1-}$ animals are resistant to CIA, while Postigo et al. show that $\mathrm{ApoE}^{-1-}$ mice are more susceptible to chronic joint disease. Important differences in these animal models that may contribute to the discrepant results include differing genetic background (C57BL/6 mice expressing $\mathrm{MHC}$ Class II $\mathrm{H}-2^{\mathrm{b}}$ in Asquith et al. versus B10.RIII mice expressing MHC Class II H-2 ${ }^{\mathrm{r}}$ in Postigo et al.) and the immunological basis of the arthritogenic trigger (anti-collagen type II (CII) antibodies in response to immunization with chicken CII in Asquith et al. and bovine CII in Postigo et al.).

We utilize an entirely different approach with the acute and semi-chronic STIA model where there is passive transfer of arthritogenic anti-glucose-6-phosphate isomerase antibodies twice a month. The arthritis that ensues in these mice has almost $100 \%$ penetrance and the mice develop maximum arthritis within 1 week after each injection of $\mathrm{K} / \mathrm{BxN}$ serum. This is in contrast to the CIA model, which has a delayed onset of disease (6-8 weeks after CII immunization) and diminished penetrance $(65-75 \%$ of control animals developing disease in the CIA models used by Asquith et al. and Postigo et al.). In addition, the semi-chronic STIA model allows us to bypass the use of adjuvant, which may complicate interpretation of the results. Moreover, this model allows us to assess the impact of semi-chronic arthritis on the development of atherosclerosis, which is a complication of longstanding disease. Here, we demonstrate that deficiency in ApoE potentiates and sustains the presence of inflammatory arthritis.

Global deletion of ApoE results in extreme elevations in serum cholesterol [27]. ApoE deficiency is known to exert effects on hematopoietic stem cell proliferation and mobilization, monocytosis and macrophage accumulation in tissue $[28,29]$. In our semi-chronic STIA model, loss of ApoE is associated with changes to the properties of synovial macrophages. In our previous study using the acute STIA model (one time passive transfer glucose6-phosphate antibodies), we demonstrated that $\mathrm{MHCII}^{+}$ macrophage subsets predominate during the propagation phase of arthritis while the $\mathrm{MHCII}^{-}$macrophage 


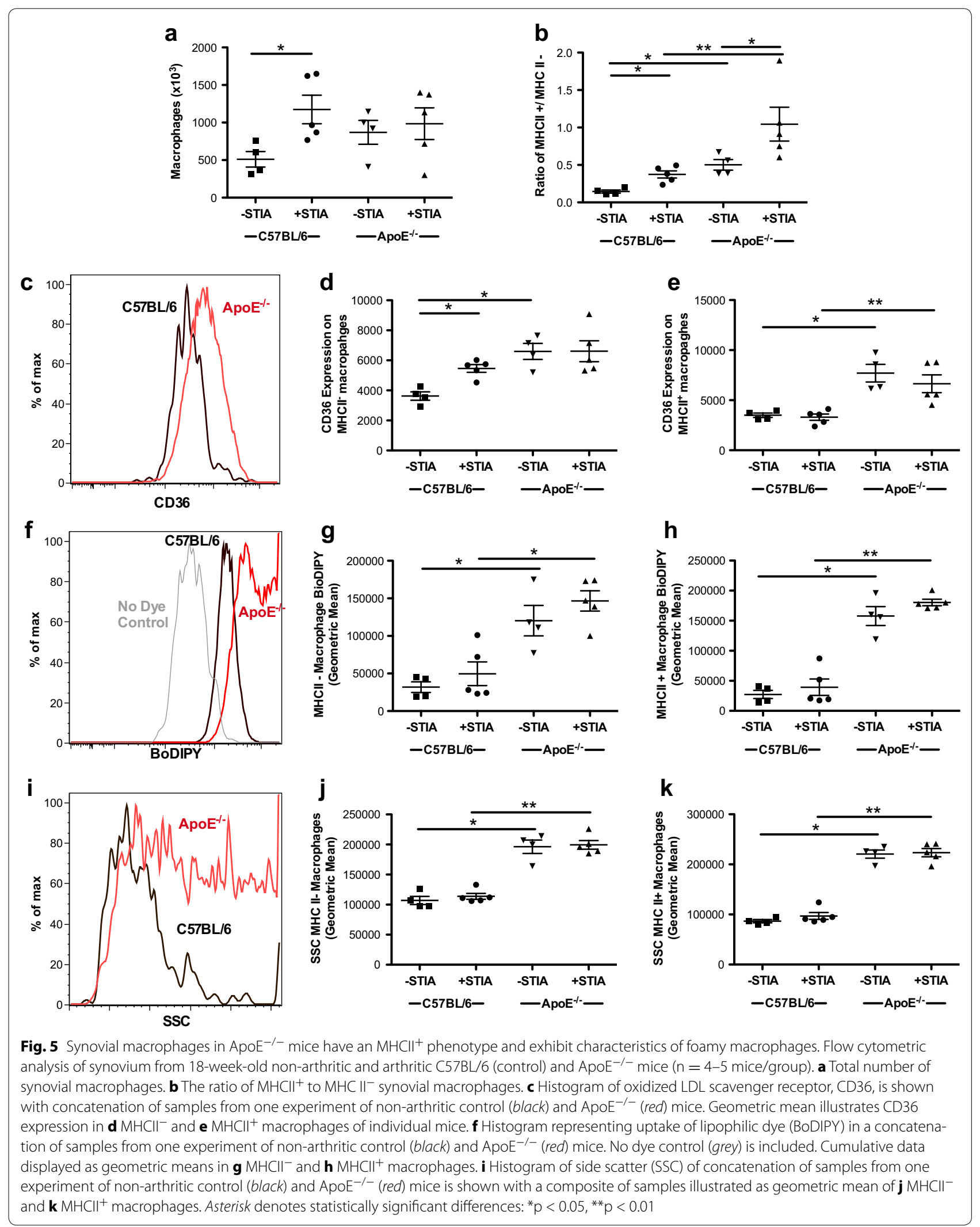




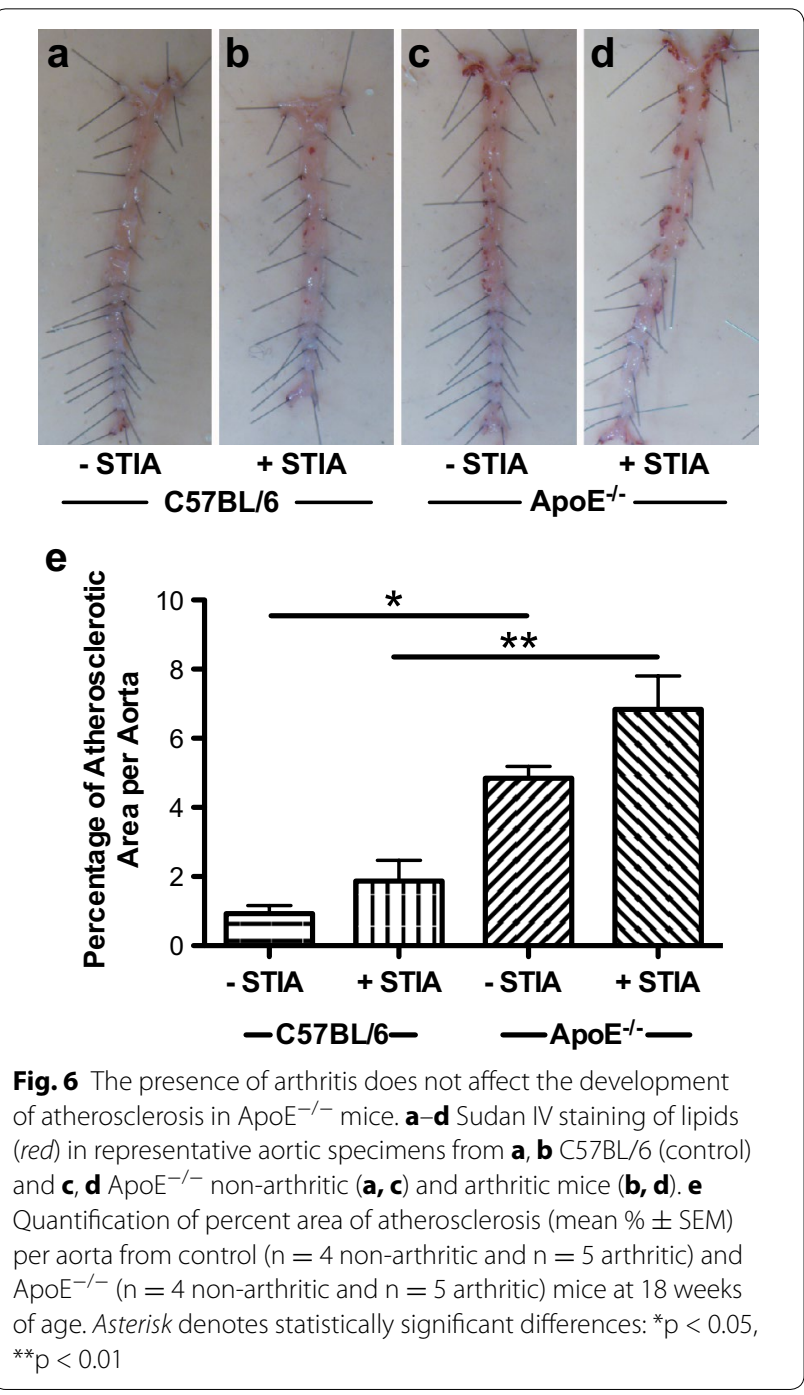

becomes the primary cell in the resolution phase of arthritis [17]. These data suggest that $\mathrm{ApoE}^{-/-}$mice may be more primed for the induction of arthritis since they exhibit a higher proportion of $\mathrm{MHCII}^{+}$to $\mathrm{MHCII}^{-}$macrophages. However, it is also possible that the increase in inflammation is related to a lack of resolution of inflammation.

$\mathrm{ApoE}^{-1-}$ mice are also able to amass foamy macrophages within the synovium. Although foamy macrophages are a well-established mediator of atherosclerotic disease, their role in the arthritic joint is not as clear. Immunohistochemical analysis of human synovial membranes reveal that foam cells are present in the synovium of RA patients [30]. In addition, a recent study observed foamy macrophages in arthritic/atherosclerotic rabbit joints [31]. Our data show increases in the number of foamy macrophages in $\mathrm{ApoE}^{-/-}$mice compared

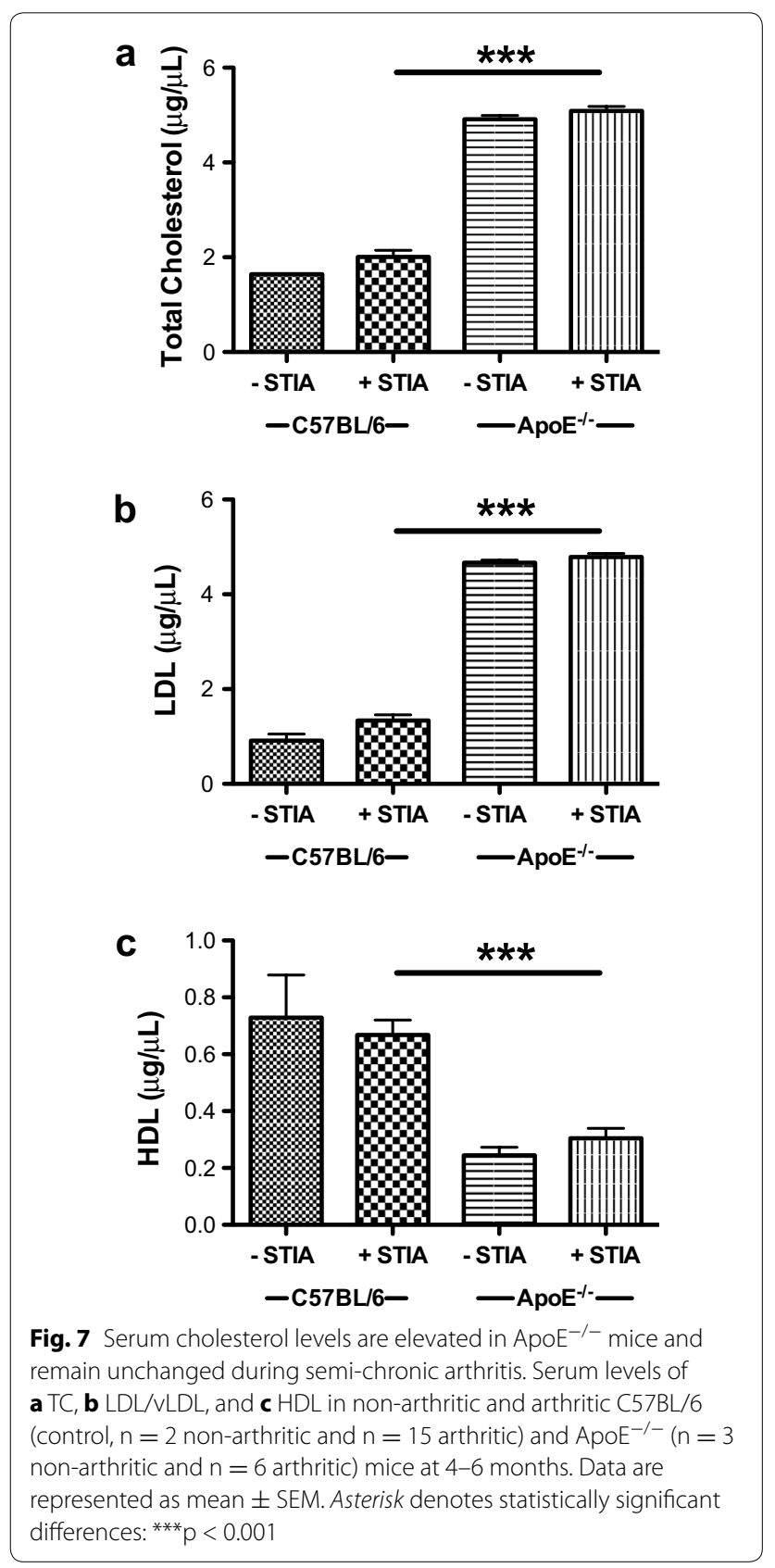

to control in the semi-chronic STIA model. Interestingly this increase in foamy macrophages is associated with higher levels of inflammation in $\mathrm{ApoE}^{-1-}$ mice (Fig. 2) but not an increase in damage to the joint or erosive disease. However, the presence of foamy macrophages appear to be associated with enhanced collagen deposition (Fig. 4) that is reminiscent of atherosclerotic plaques and further support an extension of the pathogenic role of foamy macrophages from the vasculature to the synovium. 


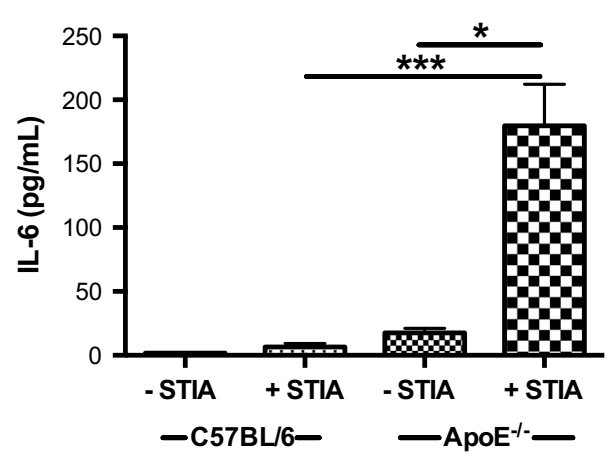

Fig. 8 Levels of circulating IL-6 are increased in arthritic $\mathrm{ApoE}^{-/-}$ mice. Serum levels of IL-6 from non-arthritic and arthritic C57BL/6 (control, $n=2$ non-arthritic and $n=13$ arthritic) and $\operatorname{ApoE}^{-/-}(n=3$ non-arthritic and $n=6$ arthritic) mice at $4-6$ months. Data are represented as mean $\pm \mathrm{SEM}$. Asterisk denotes statistically significant differences. ${ }^{*} p<0.05,{ }^{* *} p<0.001$

Our data show that $\mathrm{ApoE}^{-/-}$mice have increased expression of CD36 on synovial macrophages. This is consistent with previous reports showing elevated expression of CD36 in $\mathrm{ApoE}^{-1-}$ peritoneal macrophages [32]. CD36 is a scavenger receptor involved in the uptake of oxLDL and the subsequent development of foamy macrophages. CD36 signaling can inhibit migration and thus promote macrophage trapping within tissue. It can also stimulate the production of inflammatory cytokines $[32,33]$. It is possible that CD36 is critical for the development of arthritis in our model similar to its role in atherosclerosis where loss of CD36 improves atherosclerosis in $\mathrm{ApoE}^{-/-}$mice by over $60 \%$ [32].

The exact role of the differential expression of CD36 on $\mathrm{MHCII}^{-}$and $\mathrm{MHCII}^{+}$synovial macrophages is unclear. Data from an acute arthritis model suggest that the majority of tissue-resident macrophages are $\mathrm{MHCII}^{-}$and are involved in attenuating arthritis as opposed to the $\mathrm{MHCII}^{+}$cells that are monocyte-derived and of which a specific subpopulation is involved in propagating arthritis [17]. If these data are extrapolated to the semi-chronic arthritis model it would suggest that the potential impact of CD36 up-regulation on enhancing inflammatory arthritis is more critical in $\mathrm{MHCII}^{+}$cells, which can propagate inflammation, than the $\mathrm{MHCII}^{-}$cells which attenuate inflammation. Future studies will be needed to investigate the requirement for CD36 in synovial macrophages and to further characterize this heterogeneous macrophage population. These studies should evaluate not only the expression of surface markers on foamy macrophages isolated from the synovium in order to differentiate them from foamy macrophages within other cellular niches, but also look at gene expression on a single-cell basis.
Transcriptional profiling will also help further investigations into another potential target in our system, IL-6. Polymorphisms in IL-6 and serum levels of IL-6 have been shown to be associated with an increased risk of metabolic syndrome [34, 35]. In addition, studies evaluating the chronic inflammation associated with obesity and increased risk of metabolic syndrome have suggested that IL- 6 is an important cytokine released by adipose tissue macrophages [36]. Our data reveal large systemic increases in IL-6 during the course of inflammatory arthritis in $\mathrm{ApoE}^{-1-}$ mice. This is similar to data from a French cohort showing a correlation between serum IL-6 levels and both swollen joint count and structural damage to the joint in RA patients [37]. It is also consistent with the success of anti-IL-6 receptor therapy, tocilizumab, in treating RA [38]. However, it is likely that IL-6 is a downstream product of the foamy macrophages as it is not required for the acute STIA model [39]. IL-6 may also propagate the production of foamy macrophages, as in vitro experiments have shown that IL-6 plays a role in increasing lipid uptake by macrophages [40]. Future studies will be needed to determine the requirement for IL-6 in the development of foamy macrophages and their infiltration into the joint and the ability of foamy macrophages to produce IL-6.

Although IL-6 is also an important mediator of cardiovascular disease, its augmentation in arthritic $\mathrm{ApoE}^{-/-}$mice is not associated with a pronounced increase in atherosclerosis. It is possible that the systemic increase in IL-6 is not associated with local production of IL- 6 in both the joint and the aorta. It may also be difficult to further enhance atherosclerosis in Apo: ${ }^{-1-}$ mice, which is already at a saturated level due to a combination of both genetic and dietary factors. In support of this assertion, CIA studies performed on $\mathrm{ApoE}^{-/-}$mice show no change in atherosclerosis [41, 42]. Nonetheless this negative data is important to help understand the interplay between the presence of semichronic inflammatory arthritis and the development of atherosclerosis.

Taken together, these studies demonstrate that ApoE itself has a major effect on the development of arthritis, which may be mediated through the formation of foamy macrophages within the synovium. The identification of foamy macrophages within the inflamed arthritic joint provides a potential mechanistic link between inflammatory arthritis and atherosclerosis. Improved understanding of the connection between arthritis and atherosclerosis is crucial as we evaluate therapies that will not only improve arthritis but also decrease patients' risk of cardiovascular disease. 


\section{Conclusions}

The present study examines the relationship between inflammatory arthritis and atherosclerosis. Our model shows that ApoE is essential for limiting the development of semi-chronic inflammatory arthritis. In contrast, the combination of inflammatory arthritis and ApoE deficiency does not enhance atherosclerosis beyond the high level observed in non-arthritic $\mathrm{ApoE}^{-1-}$ mice. However, our data provide additional support that factors beyond the absolute levels of lipids may be important for the development of inflammatory arthritis in $\mathrm{ApoE}^{-1-}$ mice. Our data also support a critical role for foamy macrophages and IL- 6 production in the progression of inflammatory arthritis. Future studies may uncover the dual role for monocytes in the development of atherosclerosis and arthritis in $\mathrm{ApoE}^{-/-}$mice and address the effects of ApoE deficiency on joint foam cell formation, IL-6 production and arthritis development in a cell-type specific fashion.

\section{Additional files}

\section{Additional file 1. Antibodies utilized for flow cytometry studies.}

Additional file 2. The response to acute arthritis is similar between $\mathrm{ApoE}^{-/-}$mice and C57BL/6 mice. C57BL/6 (control) and $\mathrm{ApoE}^{-/-}$mice ( $n=6-7$ mice/group) were fed chow until 8 weeks of age, at which time they were started on a Western diet. Animals then received one injection of $\mathrm{K} / \mathrm{BxN}$ serum at 12 weeks of age. Arthritis severity was scored every other day via clinical score for 2 weeks. Data are represented as mean \pm SEM.

Additional file 3. Alteration of levels of circulating cytokines/chemokines in C57BL/6 and $\mathrm{ApoE}^{-/-}$mice with induction of arthritis. Serum levels from non-arthritic and arthritic C57BL/6 (control, $n=2$ non-arthritic and $n=13$ arthritic) and $\mathrm{ApoE}^{-/-}$( $\mathrm{n}=3$ non-arthritic and $\mathrm{n}=6$ arthritic) mice at 4-6 months. Data are represented as mean \pm SEM. ${ }^{*}$ denotes statistically significant differences. ${ }^{*} p<0.05,{ }^{* *} p<0.01,{ }^{* * *} p<0.001$.

\section{Abbreviations}

STIA: serum transfer induced arthritis; ApoE: apolipoprotein E; RA: rheumatoid arthritis; oxLDL: oxidized low-density lipoprotein; IL-6: interleukin-6.

\footnotetext{
Authors' contributions

AMA carried out arthritis studies, processed and quantified atherosclerosis staining, performed picrosirius red analysis, interpreted data, designed experiments and wrote manuscript. RS carried out arthritis studies, processed atherosclerosis staining, performed cholesterol assays, was involved in experimental design and reviewed manuscript. SR carried out arthritis studies, processed and analyzed atherosclerosis staining, performed data interpretation, was involved in experimental design and wrote manuscript. AS processed atherosclerosis staining, analyzed atherosclerosis data and reviewed the manuscript. AVM was involved in experimental design, data collection, flow analysis and edited the manuscript. GKH quantified pathologic changes in joints and assisted in writing the manuscript. SD was involved in experimental design, data collection and reviewed the manuscript. FT was involved in experimental design, data collection and reviewed the manuscript. ME was involved in experimental design and reviewed the manuscript. DEV was involved in experimental design, data interpretation and reviewed the manuscript. CMC carried out arthritis studies, performed luminex assays, processed and quantified atherosclerosis staining, performed data interpretation, designed experiments and wrote the manuscript. HP was involved in experimental design, data interpretation and wrote the manuscript. All authors read and approved the final manuscript.
}

\section{Author details}

${ }^{1}$ Division of Rheumatology, Department of Medicine, Northwestern University Feinberg School of Medicine, 240 East Huron Street, McGaw M338, Chicago, IL 60611, USA. ${ }^{2}$ Present Address: Immunoscience Exploratory Clinical and Translational Research, Bristol-Myers Squibb, Lawrenceville, NJ, USA. ${ }^{3}$ Division of Pulmonary and Critical Care, Department of Medicine, Northwestern University Feinberg School of Medicine, Chicago, IL, USA. ${ }^{4}$ Department of Pathology, Mount Sinai Hospital, New York, NY, USA. ${ }^{5}$ Division of Cardiology, Cardiovascular Research Institute, Northwestern University Feinberg School of Medicine, Chicago, IL, USA.

\section{Acknowledgements}

This work was supported by NIH Grant AR007611, NIH Loan Repayment Grant, and the American College of Rheumatology Research and Education Foundation to SR, Driskill Fellowship and NIH T32 AR007611 to AMA, American Heart Association Grant PRE21410010 to FT, NIH Grants HL051387 and HL108795 to DEV, NIH grant K01AR064313 to CMC, and NIH Grants (AR064546-01, AR050250, AR054796, Al092490 and HL108795) and Funds provided by the Solovy-Arthritis Research Society Chair in Medicine to HP.

The authors would like to thank Jungwa Lee within the Division of Preventative Medicine at Northwestern University for advice on statistical analysis, Sheila Murphy for technical support and Katherine Barnes for technical support.

\section{Competing interests}

The authors declare that they have no competing interests.

Received: 20 November 2015 Accepted: 16 May 2016

Published online: 10 June 2016

\section{References}

1. Bevaart L, Vervoordeldonk MJ, Tak PP. Evaluation of therapeutic targets in animal models of arthritis: how does it relate to rheumatoid arthritis? Arthritis Rheum. 2010;62:2192-205.

2. Avina-Zubieta JA, Choi HK, Sadatsafavi M, Etminan M, Esdaile JM, Lacaille D. Risk of cardiovascular mortality in patients with rheumatoid arthritis: a meta-analysis of observational studies. Arthritis Rheum. 2008;59:1690-7.

3. del Rincon I, Williams K, Stern MP, Freeman GL, Escalante A. High incidence of cardiovascular events in a rheumatoid arthritis cohort not explained by traditional cardiac risk factors. Arthritis Rheum. 2001:44:2737-45.

4. Meune C, Touze E, Trinquart L, Allanore Y. Trends in cardiovascular mortality in patients with rheumatoid arthritis over 50 years: a systematic review and meta-analysis of cohort studies. Rheumatology. 2009;48:1309-13.

5. Moore KJ, Sheedy FJ, Fisher EA. Macrophages in atherosclerosis: a dynamic balance. Nat Rev Immunol. 2013;13:709-21.

6. Piedrahita JA, Zhang SH, Hagaman JR, Oliver PM, Maeda N. Generation of mice carrying a mutant apolipoprotein E gene inactivated by gene targeting in embryonic stem cells. Proc Natl Acad Sci USA. 1992;89:4471-5.

7. Plump AS, Smith JD, HayekT, Aalto-Setala K, Walsh A, Verstuyft JG, Rubin EM, Breslow JL. Severe hypercholesterolemia and atherosclerosis in apolipoprotein E-deficient mice created by homologous recombination in ES cells. Cell. 1992;71:343-53.

8. Goldstein JL, Brown MS. Lipoprotein receptors and the control of plasma LDL cholesterol levels. Eur Heart J. 1992;13(Suppl B):34-6.

9. Ghiselli G, Schaefer EJ, Gascon P, Breser HB Jr. Type III hyperlipoproteinemia associated with apolipoprotein E deficiency. Science. 1981;214:1239-41.

10. Toms TE, Symmons DP, Kitas GD. Dyslipidaemia in rheumatoid arthritis: the role of inflammation, drugs, lifestyle and genetic factors. Curr Vasc Pharmacol. 2010;8:301-26.

11. Myasoedova E, Crowson CS, Kremers HM, Roger VL, Fitz-Gibbon PD, Therneau TM, Gabriel SE. Lipid paradox in rheumatoid arthritis: the impact of serum lipid measures and systemic inflammation on the risk of cardiovascular disease. Ann Rheum Dis. 2011;70:482-7.

12. Charles-Schoeman C, Lee YY, Grijalva V, Amjadi S, FitzGerald J, Ranganath VK, Taylor M, McMahon M, Paulus HE, Reddy ST. Cholesterol efflux by high density lipoproteins is impaired in patients with active rheumatoid arthritis. Ann Rheum Dis. 2012;71:1157-62. 
13. Courtenay JS, Dallman MJ, Dayan AD, Martin A, Mosedale B. Immunisation against heterologous type II collagen induces arthritis in mice. Nature. 1980;283:666-8

14. Asquith DL, Miller AM, Hueber AJ, Liew FY, Sattar N, McInnes IB. Apolipoprotein E-deficient mice are resistant to the development of collageninduced arthritis. Arthritis Rheum. 2010;62:472-7.

15. Postigo J, Genre F, Iglesias M, Fernandez-Rey M, Buelta L, Rodriguez-Rey JC, Merino J, Merino R. Exacerbation of collagen type II-induced arthritis in ApoE deficient mice in association with the expansion of Th1 and Th17 cells. Arthritis Rheum. 2011;63:971-80.

16. Korganow AS, Ji H, Mangialaio S, Duchatelle V, Pelanda R, Martin T, Degott C, Kikutani H, Rajewsky K, Pasquali JL, et al. From systemic T cell selfreactivity to organ-specific autoimmune disease via immunoglobulins. Immunity. 1999;10:451-61.

17. Misharin AV, Cuda CM, Saber R, Turner JD, Gierut AK, Haines GK 3rd, Berdnikovs S, Filer A, Clark AR, Buckley CD, et al. Nonclassical Ly6C(-) monocytes drive the development of inflammatory arthritis in mice. Cell Rep. 2014;9:591-604.

18. Mavers M, Cuda CM, Misharin AV, Gierut AK, Agrawal H, Weber E, Novack DV, Haines GK 3rd, Balomenos D, Perlman H. Cyclin-dependent kinase inhibitor p21, via its C-terminal domain, is essential for resolution of murine inflammatory arthritis. Arthritis Rheum. 2012;64:141-52.

19. Huang QQ, Birkett R, Koessler RE, Cuda CM, Haines GK 3rd, Jin JP, Perlman $H$, Pope RM. Fas signaling in macrophages promotes chronicity in K/BxN serum-induced arthritis. Arthritis Rheumatol. 2014;66:68-77.

20. Rose S, Eren M, Murphy S, Zhang H, Thaxton CS, Chowaniec J, Waters EA Meade TJ, Vaughan DE, Perlman H. A novel mouse model that develops spontaneous arthritis and is predisposed towards atherosclerosis. Ann Rheum Dis. 2013;72:89-95.

21. Scatizzi JC, Bickel E, Hutcheson J, Haines GK 3rd, Perlman H. Bim deficiency leads to exacerbation and prolongation of joint inflammation in experimental arthritis. Arthritis Rheum. 2006;54:3182-93.

22. Scatizzi JC, Hutcheson J, Pope RM, Firestein GS, Koch AE, Mavers M, Smason A, Agrawal H, Haines GK 3rd, Chandel NS, et al. Bim-BCl-2 homology 3 mimetic therapy is effective at suppressing inflammatory arthritis through the activation of myeloid cell apoptosis. Arthritis Rheum. 2010;62:441-51.

23. Mavers M, Cuda CM, Misharin AV, Gierut AK, Agrawal H, Weber E, Novack DV, Haines GK 3rd, Balomenos D, Perlman H. Cyclin-dependent kinase inhibitor p21, via its C-terminal domain, is essential for resolution of murine inflammatory arthritis. Arthritis Rheum. 2012;64:141-52.

24. Pettit AR, Ji H, von Stechow D, Muller R, Goldring SR, Choi Y, Benoist C, Gravallese EM. TRANCE/RANKL knockout mice are protected from bone erosion in a serum transfer model of arthritis. Am J Pathol. 2001;159:1689-99.

25. Aubry MC, Maradit-Kremers H, Reinalda MS, Crowson CS, Edwards WD, Gabriel SE. Differences in atherosclerotic coronary heart disease between subjects with and without rheumatoid arthritis. J Rheumatol. 2007;34:937-42

26. McCarey DW, Mclnnes IB, Madhok R, Hampson R, Scherbakov O, Ford I, Capell HA, Sattar N. Trial of atorvastatin in rheumatoid arthritis (TARA): double-blind, randomised placebo-controlled trial. Lancet. 2004;363:2015-21.

27. Whitman SC. A practical approach to using mice in atherosclerosis research. Clin Biochem Rev. 2004:25:81-93.

28. Murphy AJ, Akhtari M, Tolani S, Pagler T, Bijl N, Kuo CL, Wang M, Sanson M, Abramowicz S, Welch C, et al. ApoE regulates hematopoietic stem cell proliferation, monocytosis, and monocyte accumulation in atherosclerotic lesions in mice. J Clin Invest. 2011;121:4138-49.
29. Swirski FK, Libby P, Aikawa E, Alcaide P, Luscinskas FW, Weissleder R, Pittet MJ. Ly-6Chi monocytes dominate hypercholesterolemia-associated monocytosis and give rise to macrophages in atheromata. J Clin Invest. 2007; 117:195-205.

30. Winyard PG, Tatzber F, Esterbauer H, Kus ML, Blake DR, Morris CJ. Presence of foam cells containing oxidised low density lipoprotein in the synovial membrane from patients with rheumatoid arthritis. Ann Rheum Dis. 1993;52:677-80.

31. Prieto-Potin I, Roman-Blas JA, Martinez-Calatrava MJ, Gomez R, Largo R, Herrero-Beaumont G. Hypercholesterolemia boosts joint destruction in chronic arthritis. An experimental model aggravated by foam macrophage infiltration. Arthritis Res Ther. 2013;15:R81.

32. Kuchibhotla S, Vanegas D, Kennedy DJ, Guy E, Nimako G, Morton RE, Febbraio M. Absence of CD36 protects against atherosclerosis in ApoE knock-out mice with no additional protection provided by absence of scavenger receptor A I/II. Cardiovasc Res. 2008;78:185-96.

33. Park YM. CD36, a scavenger receptor implicated in atherosclerosis. Exp Mol Med. 2014;46:e99.

34. Sadashiv, Tiwari S, Gupta V, Paul BN, Kumar S, Chandra A, Dhananjai S, Negi MP, Ghatak A. IL-6 gene expression in adipose tissue of postmenopausal women and its association with metabolic risk factors. Mol Cell Endocrinol. 2015:399:87-94.

35. Povel CM, Boer JM, Reiling E, Feskens EJ. Genetic variants and the metabolic syndrome: a systematic review. Obes Rev. 2011;12:952-67.

36. Biswas SK, Mantovani A. Orchestration of metabolism by macrophages. Cell Metab. 2012;15:432-7.

37. Baillet A, Gossec L, Paternotte S, Etcheto A, Combe B, Meyer O, Mariette $X$, Gottenberg JE, Dougados M. Evaluation of serum interleukin-6 level as a surrogate marker of synovial inflammation and as a factor of structura progression in early rheumatoid arthritis: results from a French national multicenter cohort. Arthritis Care Res (Hoboken). 2015;67:905-12.

38. Maini RN, Taylor PC, Szechinski J, Pavelka K, Broll J, Balint G, Emery P, Raemen F, Petersen J, Smolen J, et al. Double-blind randomized controlled clinical trial of the interleukin-6 receptor antagonist, tocilizumab, in European patients with rheumatoid arthritis who had an incomplete response to methotrexate. Arthritis Rheum. 2006;54:2817-29.

39. Ji H, Pettit A, Ohmura K, Ortiz-Lopez A, Duchatelle V, Degott C, Gravallese E, Mathis D, Benoist C. Critical roles for interleukin 1 and tumor necrosis factor alpha in antibody-induced arthritis. J Exp Med. 2002;196:77-85

40. Zhou C, Lei H, Chen Y, Liu Q, Li LC, Moorhead JF, Varghese Z, Ruan XZ. Enhanced SCAP glycosylation by inflammation induces macrophage foam cell formation. PLoS One. 2013;8:e75650.

41. Asquith DL, Miller AM, Hueber AJ, Liew FY, Sattar N, McInnes IB. Apolipoprotein E-deficient mice are resistant to the development of collageninduced arthritis. Arthritis Rheum. 2010;62:472-7.

42. Postigo J, Genre F, Iglesias M, Fernandez-Rey M, Buelta L, Carlos Rodriguez-Rey J, Merino J, Merino R. Exacerbation of type II collageninduced arthritis in apolipoprotein E-deficient mice in association with the expansion of Th1 and Th17 cells. Arthritis Rheum. 2011;63:971-80.

\section{Submit your next manuscript to BioMed Central and we will help you at every step:}

- We accept pre-submission inquiries

- Our selector tool helps you to find the most relevant journal

- We provide round the clock customer support

- Convenient online submission

- Thorough peer review

- Inclusion in PubMed and all major indexing services

- Maximum visibility for your research

Submit your manuscript at www.biomedcentral com/submit
C BioMed Central 